\title{
BUILDING THE RADIOCARBON CHRONOLOGY FOR THE ARCHAEOLOGICAL SITE UFA-II, BASHKORTOSTAN, RUSSIA: IS THIS THE ELUSIVE "BASHKORT" OF MEDIEVAL SOURCES?
}

\author{
Vladimir A Levchenko \\ Australian Nuclear Science and Technology Organisation (ANSTO), Locked Bag 2001 Kirrawee DC, NSW, 2232 Australia. \\ Corresponding author. Email: vladimir.levchenko@ansto.gov.au. \\ Flarit A Sungatov \\ Academy of Sciences of Republic of Bashkortostan, 15 Kirova St., Ufa, Republic of Bashkortostan 450077, Russian \\ Federation.
}

\begin{abstract}
A suite of accelerator mass spectrometry (AMS) radiocarbon dates for the Ufa-II archaeological site in Bashkortostan, Russia, is obtained for the first time. Dating was done on charcoal samples from a sequence of cultural deposits collected during the 2011 digging season. An age-depth chronology is established using the Bayesian deposition General Outlier P_Sequence model. The oldest age for the site at the horizon immediately over the sterile ground was cal AD 137-237 (68\% probability), corresponding to the beginning of site occupation. The youngest ${ }^{14} \mathrm{C}$ date found was late 6 th to early 7 th century cal $\mathrm{AD}$ for the extensive planked boardwalks unearthed at the site. The ${ }^{14} \mathrm{C}$ dates are in good agreement with archaeological determinations based on discovered artifacts.
\end{abstract}

\section{INTRODUCTION}

The genesis of the Bashkir people is one of the core and still unresolved issues for ancient and Medieval history of the Southern Urals and adjacent regions. It has long been believed that the Bashkir were nomads since their beginning and until 16-17th centuries AD, without any signs of sedentary culture. This opinion can be traced back to a brief note of William of Rubruck, who when passing through the Southern Ural steppes in AD 1253-1255 referred to Bashkir as "shepherds having no city" (Jackson 1990). However, for the same period the Arabian geographer and historian Al-Idrisi described in detail a number of cities in the land of Bashkir (Bombaci et al. 1970). Later authors supported this, for example Ibn Khaldoun in 14th century named the city of Bashkort as one of the biggest in the Golden Horde (De Slane 1863). Western European cartographers of the 14-16th centuries placed the town on the banks of the Belaya River at the mouth of its tributary Ufa, which is within the boundary of the modern city of Ufa (Psyanchin 2007).

These accounts suggest that it was erroneous to consider the Bashkir as a purely nomadic people without any settled urban culture. However, convincing archaeological evidence was required to prove this unequivocally. Archaeological surveys of the province in the 1970s-1980s uncovered a number of archaeological sites in partly forested regions of the steppe-remnants of ancient fortified settlements, with a variety of developed crafts spanning from the Bronze Age until the 15-16th centuries AD. The Ufa-II site is central to this network of urban nodes.

In 2008, a joint communiqué of the Prime Minister of the Republic of Bashkortostan and the UNESCO Deputy Director General stated the intention to collaborate for the safeguarding of, and archaeological research and fieldwork at, the site of historical and archaeological monument "UfaII Ancient City Centre.” The current research forms part of the agreed endeavor.

\section{UFA-II ARCHAEOLOGICAL SITE}

The study site is situated in the historical center of Ufa, the capital of Bashkortostan Republic, Russia, on the right bank of the Belaya River, not far from the confluence of its tributaries Ufa and Dema

(C) 2013 by the Arizona Board of Regents on behalf of the University of Arizona

Proceedings of the 21st International Radiocarbon Conference edited by A J T Jull \& C Hatté

RADIOCARBON, Vol 55, Nr 2-3, 2013, p 1278-1285 


\section{$V$ A Levchenko \& F A Sungatov}

$\left(54^{\circ} 42.99^{\prime} \mathrm{N}\right.$ to $\left.55^{\circ} 57.46^{\prime} \mathrm{E}\right)$. In ancient times, Ufa-II was positioned on a river-facing promontory, bounded on 2 sides by deep ravines, and on the field side by a broad ravine and a strong fortification. The site has significant cultural deposits, reaching up to $4 \mathrm{~m}$ in thickness. This settlement is the largest archaeological site of this quality in the Southern Urals. The locality is surrounded in close proximity by remnants of 6 other contemporary fortified settlements, about 10 villages and a necropolis of many tumuli and in-ground row burials. The existence of the site has been known to the local inhabitants for a long time. However, the first exploratory digs were only made in 1957-1958, uncovering thick cultural deposits that suggested the existence of permanent early Medieval settlements in the land of Bashkir (Mazhitov 1973) for the first time. This suggestion was in stark contrast with the then-dominant point of view of the Bashkir as purely nomads until the arrival of Russian settlers and foundation of Ufa town in AD 1573. No further studies were undertaken until 2006 when a full archaeological excavation commenced in response to imminent site redevelopment. Unfortunately, part of the settlement area had already been destroyed by modern construction and roads by that time. However, a section, used by locals for vegetable plots, was preserved relatively undisturbed.

Extensive archaeological diggings of this section from 2006 to 2011, shown in Figure 1, produced extraordinary results. Many remnants of unique objects of monumental construction were discovered, such as fortification walls, dwellings, and other structures built with rammed earth/clay in formwork and adobe bricks. The remnants of at least 2 streets crossing each other, paved with 4-5 layered planked boardwalks, were discovered next to the remnants of wooden-adobe dwellings. These discoveries characterize the Ufa-II and related sites (the necropolis) as a large settlement built according to a predetermined plan (Mazhitov et al. 2008). The diverse artifact finds allowed tentative dating of the active phase of the settlement to the 4th to 14th centuries $\mathrm{AD}$ with probable extension of the beginning date to the 2nd-3rd centuries AD.

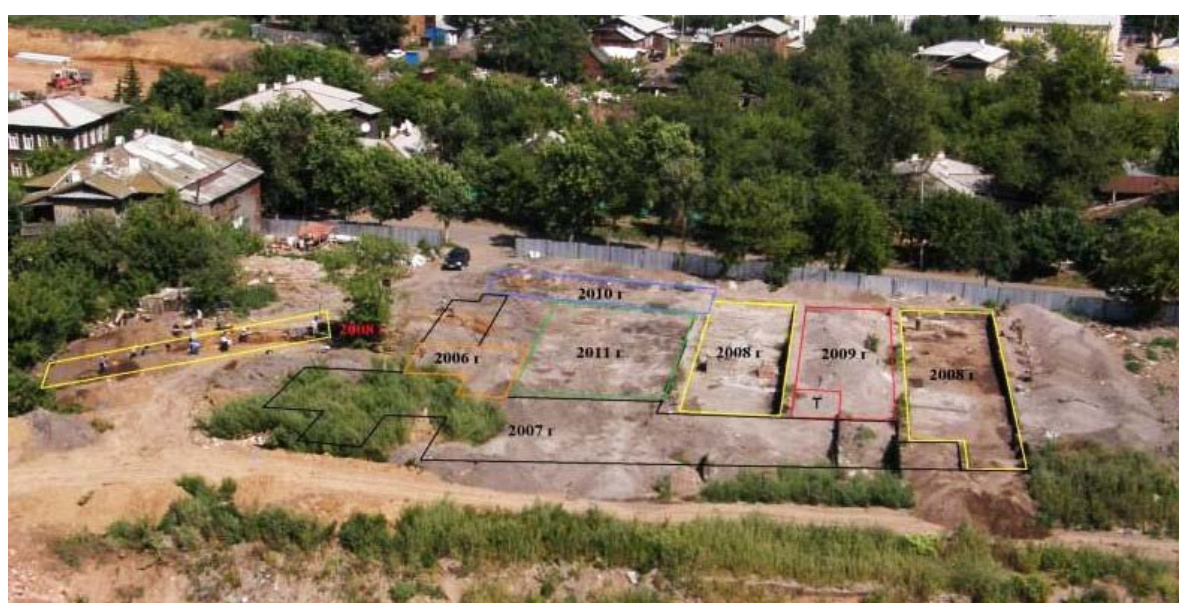

Figure 1 The Ufa-II archaeological site aerial view with individual annual seasons’ digs marked

In order to advance our understanding of this site, a better established and resolved physical chronology was required. Without a reliable chronology, it is impossible to consider the beginnings and final stages of the site, its role and place within other antiquities of the Southern Urals, and to provide proof for the Medieval narrative and cartographic data of the existence of "Bashkort." 
${ }^{14}$ C Chronology for the Archaeological Site Ufa-II

\section{SAMPLE SELECTION AND PROCESSING}

Results of ${ }^{14} \mathrm{C}$ dating, based on charcoal and wood samples collected along the deposit sequence, were chosen to construct the age-depth chronology. Samples of charcoal and wood were collected at 4 spots. Most came from the walls of the 2011 season dig (see Figure 1): 9 from the southern wall (OZO607-615, Figure 2) and another 4 from the northern wall (OZO616-619, Figure 3). The sample descriptions and identifications are presented in Table 1.

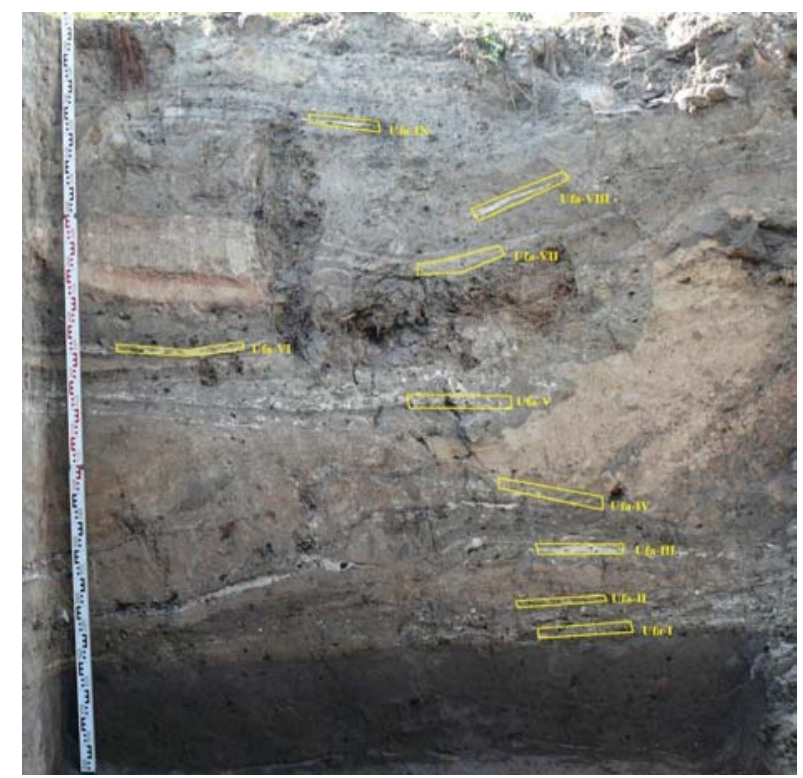

Figure 2 Southern wall sampling sequence. See Table 1 for sample descriptions.

The sedimentary sequence on both walls demonstrated no sterile layers among cultural deposits, indicating no lapses in site occupation. Where the sedimentary sequence exhibited cut features or redeposited layers, which were identified on the southern wall and absent on the northern, they were avoided, and only unperturbed layers containing some charcoal were studied. Charcoal grains, embedded in the sediments, were collected and visually inspected under a magnifying glass. Only those that had the appearance of originating from thin twigs and small branches were chosen in an effort to minimize as much as possible the inherited wood age. Unfortunately, no charred seeds or similar annual material was found. Samples OZO620-622 were taken from the dig where a planked boardwalk was unearthed. The first two, 1 charcoal and 1 wood, were taken from the eastern wall of the dig from the layer immediately under the boardwalk (Figure 4). The last sample, OZO622, came from the opposite western wall from the layer immediately above the boardwalk. Upon collection, samples were placed in sealed sterile plastic bags and sent to the ANSTO laboratories for processing.

Charcoal samples were pretreated using the standard acid-base-acid (ABA) procedure following the protocol described in Hatté et al. (2001). During the alkali stage, a relatively low presence of humic acids was observed. Wood was pretreated to holocellulose to remove possible contaminants (Hedges 1992; Leavitt and Danzer 1993). Pretreated samples were combusted in evacuated, sealed quartz tubes in the presence of purified $\mathrm{CuO}$ and Ag wire (Vandeputte et al. 1996). The $\mathrm{CO}_{2}$ produced was dried and collected, the yield determined, and then it was converted to graphite by reduction with 


\section{A Levchenko \& F A Sungatov}

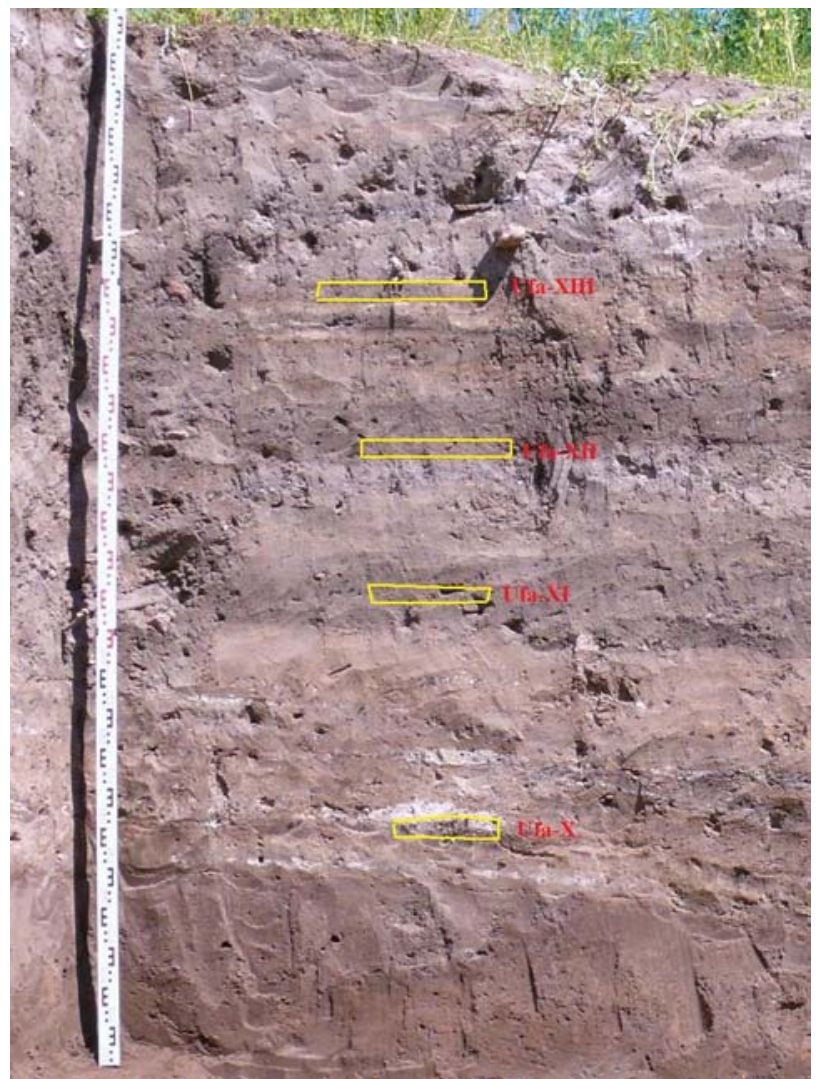

Figure 3 Northern wall sampling sequence

Table 1 Sample identification and description.

\begin{tabular}{llll}
\hline $\begin{array}{l}\text { Distance from sterile } \\
\text { ground }(\mathrm{cm})\end{array}$ & $\begin{array}{c}\text { Sample } \\
\text { material }\end{array}$ & Submitter ID & Sample description \\
\hline $\begin{array}{l}\text { Southern wall samples } \\
0-5\end{array}$ & $\begin{array}{ll}\text { Charcoal } \\
\text { 45-50 }\end{array}$ & Ufa-I & Immediately above sterile ground \\
$65-70$ & Charcoal & Ufa-II & No associated features \\
$85-90$ & Charcoal & Ufa-III & No associated features \\
$125-130$ & Charcoal & Ufa-IV & No associated features \\
$150-155$ & Charcoal & Ufa-V & Under the dwelling \\
$170-175$ & Charcoal & Ufa-VI & Dwelling infill \\
$205-210$ & Charcoal & Ufa-VII & Under the overlying dwelling \\
$245-250$ & Charcoal & Ufa-VIII & Dwelling infill \\
Northern wall samples & Charcoal & Ufa-IX & Under the overlying dwelling \\
$5-10$ & & \\
$70-75$ & Charcoal & Ufa-X & Above sterile ground \\
$115-120$ & Charcoal & Ufa-XI & Under the dwelling \\
$145-150$ & Charcoal & Ufa-XII & Over the dwelling \\
Samples bracketing planked boardwalk & Under the dwelling \\
$90-95$ & Charcoal & Ufa-XIII & \\
$90-95$ & Wood & Ufa-XIV & Under the boardwalk \\
$100-105$ & Charcoal & Ufa-XV & Under the boardwalk \\
\hline & Charcoal & Ufa-XVI & Over the boardwalk \\
\hline
\end{tabular}


${ }^{14} \mathrm{C}$ Chronology for the Archaeological Site Ufa-II

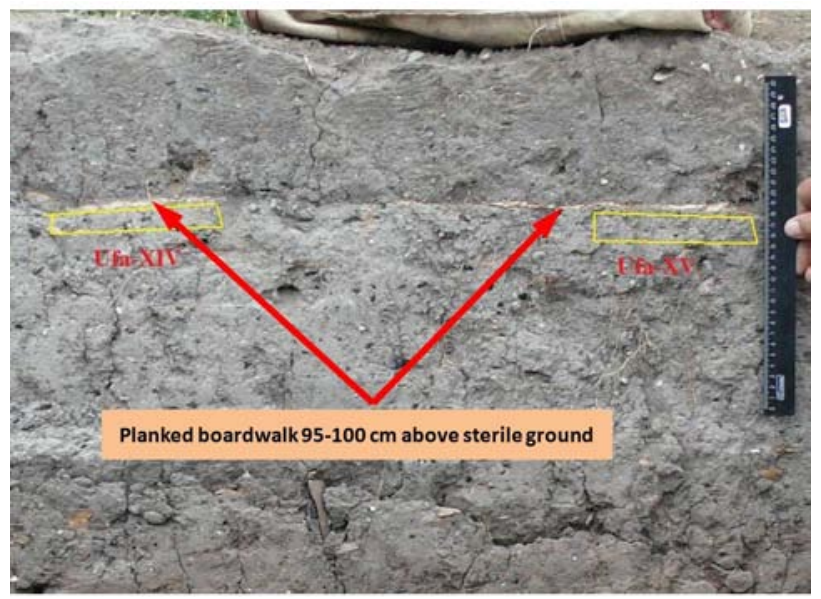

Figure 4 Samples underlying the planked boardwalk

excess hydrogen over iron catalyst to produce targets for AMS measurements (Jull et al. 1986). ${ }^{14} \mathrm{C}$ accelerator mass spectrometry (AMS) measurements were performed on the STAR 2MV Tandetron to at least $0.35 \%$ statistical precision (Fink et al. 2004).

\section{RESULTS AND DISCUSSION}

$\delta^{13} \mathrm{C}$ and ${ }^{14} \mathrm{C}$ measurement results are presented in Table 2 . The $\delta^{13} \mathrm{C}$ values were obtained using a separate EA-IRMS determination on graphite targets used for AMS measurements. The high precision achieved in AMS measurements allowed reducing overall ${ }^{14} \mathrm{C}$ age errors to $30-40$ yr. The ${ }^{14} \mathrm{C}$ ages presented are rounded to the nearest $5 \mathrm{yr}$. We followed the procedures for calculating the pMC value, ${ }^{14} \mathrm{C}$ ages, and the rounding convention from Stuiver and Polach (1977). Age calibration was done using the OxCal v 4.1 program last updated in 2010 (Bronk Ramsey 2009a) with the IntCal09 Northern Hemisphere curve (Reimer et al. 2009). The age-depth chronology was constructed with Bayesian data analysis and deposition models again using the OxCal v 4.1 software (Bronk Ramsey 2008). Since the selection of charcoal material was not ideal, and some minor layer disturbance could not be completely excluded, the presence of an additional error component in the obtained ages could result. To handle this, the General Outlier P_Sequence model, with a small $k$ value of 0.3 in order to get a good flexibility, and prior outlier probability of 0.1 for faster conversion, was constructed for northern and southern walls of the dig separately. The A (agreement) model index of the northern wall Outlier P_Sequence is 68\%, which is over the acceptance threshold A index of $60 \%$ (Figure 5).

For the southern wall Outlier P_Sequence model, the A model index was 46\%, which indicated the presence of an irreconcilable outlier (Bronk Ramsey 2009b). After exploring different modeling approaches and model parameters, the model was reconciled with minimal intervention: 1 outlier (OZO614-Ufa-VIII) was suggested in the southern wall chronology being about $100 \mathrm{yr}$ older. This can be easily explained by the presence of "old wood"-probably an unfortunate selection of a charcoal piece from inner sections of a log. The other very plausible explanation is that since the sample came from dwelling infill, it might reflect some reworked material. Excluding this 1 date improved the A model index for the Southern General Outlier P_Sequence chronology model to 62\%, making it acceptable (Figure 6a,b). The OxCal code used for this model is available as a Supplementary file accompanying the online version of this article. 


\section{A Levchenko \& F A Sungatov}

Table 2 Results of ${ }^{14} \mathrm{C}$ determinations.

\begin{tabular}{|c|c|c|c|c|}
\hline ANSTO code & Submitter ID & $\begin{array}{l}\delta^{13} \mathrm{C} \\
(\%)\end{array}$ & $\begin{array}{l}\text { pMC } \\
(1 \sigma)\end{array}$ & $\begin{array}{l}{ }^{14} \mathrm{C} \text { age } \\
\text { yr BP }(1 \sigma)\end{array}$ \\
\hline \multicolumn{5}{|c|}{ Southern wall samples } \\
\hline OZO607 & Ufa-I & -25.5 & $79.76 \pm 0.36$ & $1815 \pm 40$ \\
\hline OZO608 & Ufa-II & -25.7 & $79.56 \pm 0.39$ & $1835 \pm 40$ \\
\hline OZO609 & Ufa-III & -23.0 & $78.15 \pm 0.31$ & $1980 \pm 35$ \\
\hline OZO610 & Ufa-IV & -24.2 & $79.84 \pm 0.34$ & $1810 \pm 35$ \\
\hline OZO611 & Ufa-V & -26.6 & $81.29 \pm 0.28$ & $1665 \pm 30$ \\
\hline OZO612 & Ufa-VI & -24.0 & $80.62 \pm 0.27$ & $1730 \pm 30$ \\
\hline OZO613 & Ufa-VII & -25.1 & $81.28 \pm 0.32$ & $1665 \pm 35$ \\
\hline OZO614 & Ufa- & -23.9 & $79.64 \pm 0.34$ & $1830 \pm 35$ \\
\hline OZO615 & Ufa-IX & -24.4 & $80.85 \pm 0.32$ & $1710 \pm 35$ \\
\hline \multicolumn{5}{|c|}{ Northern wall samples } \\
\hline OZO616 & Ufa-X & -25.7 & 80.56 & $1735 \pm 35$ \\
\hline OZO617 & Ufa- & -23.7 & 80. & +35 \\
\hline OZO618 & Ufa- & -26.5 & $82.04 \pm 0.27$ & $1590 \pm 30$ \\
\hline OZO619 & Ufa-XIII & -23.2 & $80.96 \pm 0.34$ & $1695 \pm 35$ \\
\hline \multicolumn{5}{|c|}{ Samples bracketing planked boardwalk } \\
\hline OZO620 & Ufa-XIV & -22.4 & $80.68 \pm 0.34$ & $1725 \pm 35$ \\
\hline OZO621 & Ufa-XV & -23.4 & $83.30 \pm 0.35$ & $1470 \pm 35$ \\
\hline OZO622 & Ufa-XVI & -22.8 & $83.16 \pm 0.33$ & $1480 \pm 35$ \\
\hline
\end{tabular}

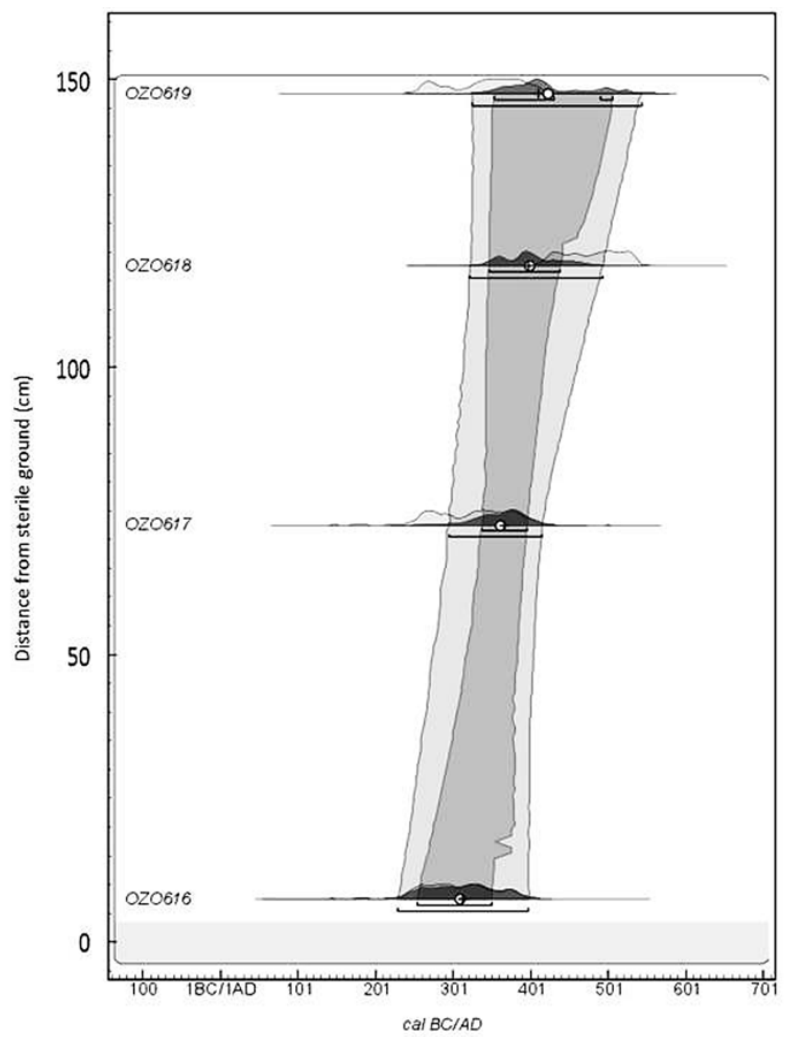

Figure 5 Northern wall age-depth model: $1 \sigma$ and $2 \sigma$ confidence intervals are shown in shades of gray for every sample. 

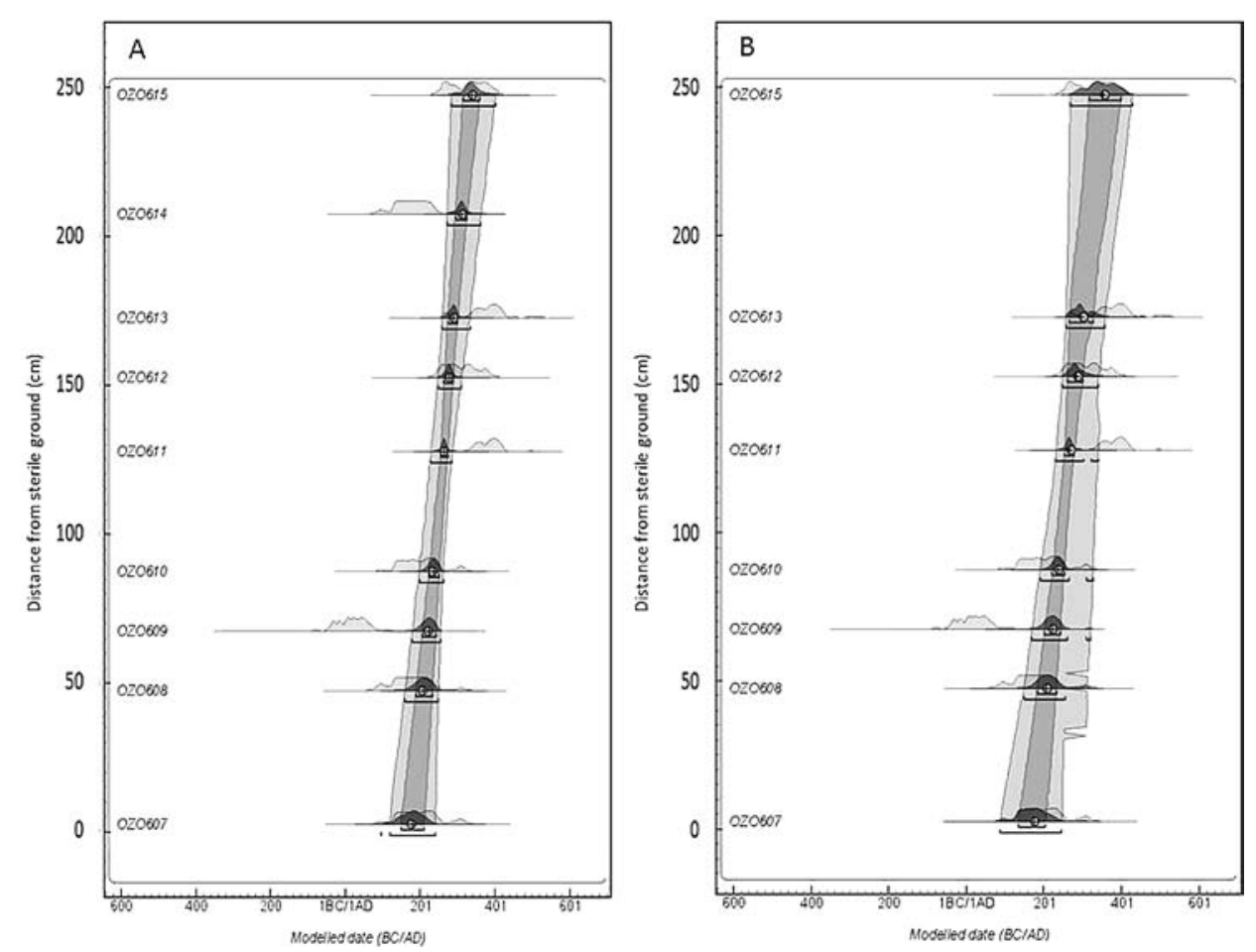

Figure 6 Southern wall age-depth models, with outlier (OZO614) present (A) and removed (B): $1 \sigma$ and $2 \sigma$ confidence intervals are shown in shades of gray for every sample.

Charcoal samples OZO621 and OZO622, bracketing the planked boardwalk layer from below and above respectively, allow us to state that it existed for $\sim 75 \mathrm{yr}$, from the middle of the 6th to first quarter of the 7th century AD (Figure 7).

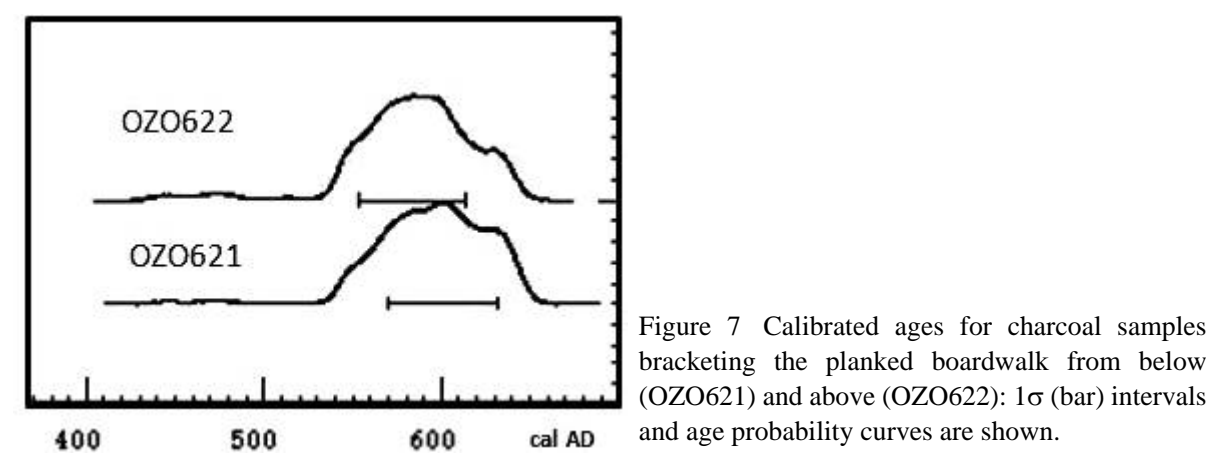

Tentative archaeological dating based on artifacts gave a much wider interval including the 6th to 8th centuries AD. The sample of wood from the layer underlying the boardwalk, OZO620, produced an age up to $250 \mathrm{yr}$ older, out of context with its surrounding. This sampling will be repeated in a new season and the cause of the discrepancy investigated. 


\section{$V$ A Levchenko \& F A Sungatov}

\section{CONCLUSIONS}

${ }^{14} \mathrm{C}$ analyses of samples from deposit layers of the Ufa-II archaeological site produced calibrated ages spanning from the first half of the 2nd century AD to the second half of the 7th century AD. The ages are in good agreement with dates based on archaeological material. ${ }^{14} \mathrm{C}$ age analysis for the horizon immediately above the sterile ground allowed an accurate determination of the earliest signs of site occupation in the 2nd or very beginning of the 3rd century AD. The age-depth depositional model constructed with Bayesian analysis of obtained ${ }^{14} \mathrm{C}$ date sequences demonstrated a more or less uniform accumulation of deposits over about 4 centuries of site existence with only 1 outlier sample, which can be plausibly explained as reworked material present in dwelling infill.

The youngest ${ }^{14} \mathrm{C}$ calibrated ages relate to the planked boardwalk period at the end of the 6th to beginning of the 7th centuries $\mathrm{AD}$; the upper $0.5-0.8 \mathrm{~m}$ of the deposit sequence has not been ${ }^{14} \mathrm{C}$ dated yet. This analysis is planned for the next excavation season and is necessary to determine whether the proven period of site existence extends to the times covered by ancient chronicles. Without that, it is not yet possible to give a definitive answer if this settlement is a good candidate for the elusive Medieval Bashkort. In addition, resampling of material that produced deviating dates to investigate the possible causes is scheduled. Direct ${ }^{14} \mathrm{C}$ dating of a number of discovered carbonbearing artifacts is also planned.

\section{REFERENCES}

Bombaci A, Rizzitano U, Rubinacci R, Vegliari LV, editors. 1970-1978. Muhammad Al-Idrisi. Opus geographicum: sive "Liber ad eorum delectationem qui terras peragrare studeant.” (9 Fascicles). Naples: Istituto Universitario Orientale.

Bronk Ramsey C. 2008. Deposition models for chronological records. Quaternary Science Reviews 27(1-2): 42-60.

Bronk Ramsey C. 2009a. Bayesian analysis of radiocarbon dates. Radiocarbon 51(1):337-60.

Bronk Ramsey, C. 2009b. Dealing with outliers and offsets in radiocarbon dating. Radiocarbon 51(3):102345.

De Slane M, translator. 1863. Ibn Khaldoun. Les Prolegomenes. Paris: Premiere Partie. 161 p.

Fink D, Hotchkis M Hua Q, Jacobsen G, Smith AM, Zoppi U, Child D, Mifsud C, van der Gaast H, Williams A, Williams M. 2004. The ANTARES AMS facility at ANSTO. Nuclear Instruments and Methods in Physics Research B 223-224:109-15.

Hatté C, Morvan J, Noury C, Paterne M. 2001. Is classical acid-alkali-acid treatment responsible for contamination? An alternative proposition. Radiocarbon 43(2A):177-82.

Hedges REM. 1992. Sample treatment strategies in radiocarbon dating. In: Taylor RE, Long A, Kra RS, editors. Radiocarbon After Four Decades: An Interdisciplinary Perspective. New York: Springer-Verlag. p 165-83.

Jackson P, editor. 1990. Ruysbroeck, Willem van. The Mission of Friar William of Rubruck: His Journey to the Court of the Great Khan Möngke, 1253-1255. London: Hakluyt Society. 328 p.
Jull AJT, Donahue DJ, Hathaway AL, Linick TW, Toolin LJ. 1986. Production of graphite targets by deposition from $\mathrm{CO} / \mathrm{H}_{2}$ for precision accelerator ${ }^{14} \mathrm{C}$ measurements. Radiocarbon 28(2A):191-7.

Leavitt SW, Danzer SR. 1993. Method for batch processing small wood samples to holocellulose for stablecarbon isotope analysis. Analytical Chemistry 65(1): 87-9.

Mazhitov NA. 1973. Mysteries of Ancient Ural. Ufa. 185 p. In Russian.

Mazhitov NA, Sungatov FA, Sultanova AN. 2008. Treasures of Ancient Ufa. Ufa: Bashkir State University. 112 p. In Russian.

Psyanchin AV. 2007. Mon ET URBIS. Ural Mountains and Ufa city in European cartographic tradition. Bashkortostan Archives 1:17-23. In Russian.

Reimer PJ, Baillie MGL, Bard E, Bayliss A, Beck JW, Blackwell PG, Bronk Ramsey C, Buck CE, Burr GS, Edwards RL, Friedrich M, Grootes PM, Guilderson TP, Hajdas I, Heaton TJ, Hogg AG, Hughen KA, Kaiser KF, Kromer B, McCormac FG, Manning SW, Reimer RW, Richards DA, Southon JR., Talamo S, Turney CSM, van der Plicht J, Weyhenmeyer CE. 2009. IntCal09 and Marine09 radiocarbon age calibration curves, 0-50,000 years cal BP. Radiocarbon 51(4): 1111-50.

Stuiver M, Polach HA. 1977. Discussion: reporting of ${ }^{14} \mathrm{C}$ data. Radiocarbon 19(3):355-63.

Vandeputte K, Moens L, Dams R. 1996. Improved sealed-tube combustion of organic samples for stable isotope analysis, radiocarbon dating and percent carbon determinations. Analytical Letters 29(15):276173. 